\title{
Perestroika in the Soviet Union's health system
}

\author{
Calum R Paton
}

Centre for Health Planning and Management, University of Keele, Keele, Staffordshire ST5 5SP C R Paton, DPHIL, senior lecturer

BrMed f 1989;299:45-6

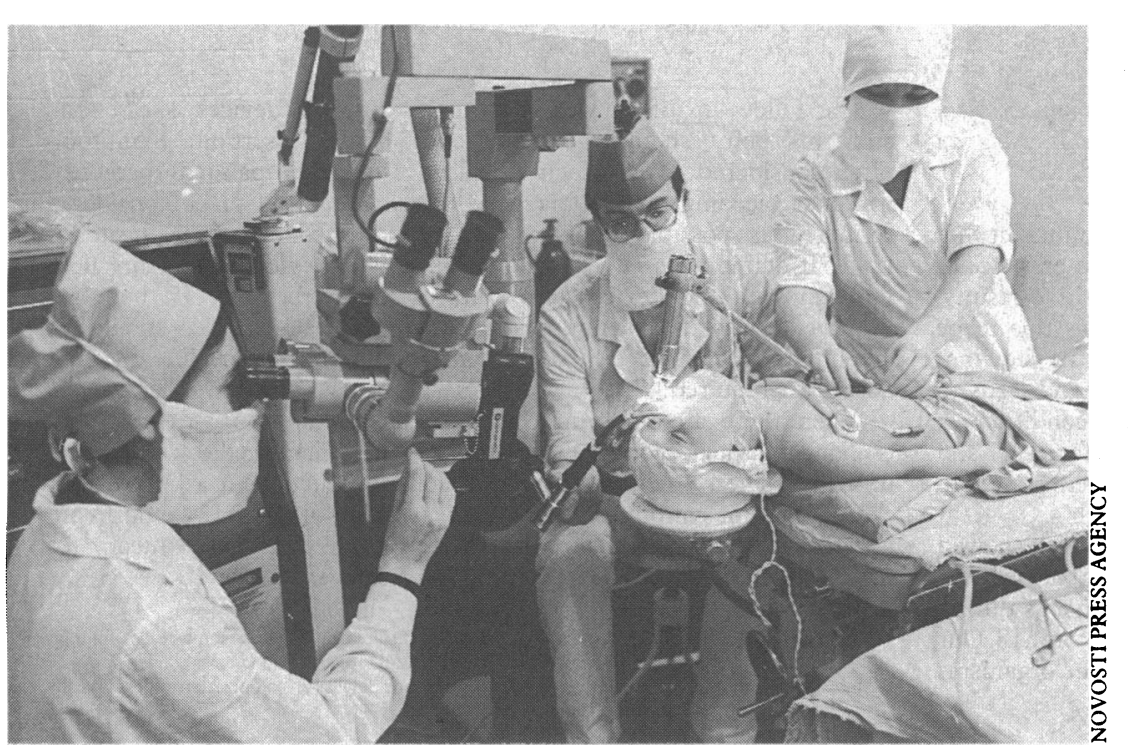

Microsurgery in the USSR towards paying doctors by the number of patients treated. New clinics and a primary care service have been established for the paying customer, but at relatively cheap rates. Reforms in dentistry are also being planned. Other innovations include greater cooperation with the West, such as the purchase of equipment and trade in general.
Recent experiments in the Soviet Union mirror the debates in the United Kingdom about improving incentives in health care. The most interesting innovation to emerge under perestroika is a pilot project in Leningrad and at two other sites which could radically change the financing of hospitals. Hitherto, the budget has gone from the ministry to the hospitals and to the polyclinics by bureaucratic procedure, a scene familiar in Britain. In future, however, the polyclinics (several under the territorial aegis of one hospital) will hold the budget. The hospital will be paid by the polyclinic for treatment carried out, and this payment apparently includes all costs from patient care to ancillary services and supplies. The polyclinic will receive something resembling a capitation fee and will pay the hospital at a fixed rate per operation.

In February 1987 Yevgeny Chazov became minister of public health in the Soviet Union. Already known in the West through International Physicians for the Prevention of Nuclear War, Chazov is a reformer and is promoting a policy of honesty about the health system. He wants to go beyond collecting mere quantitative data on inputs and move on to measuring achievement and output. Until recently crude quantification has dominated the health care statistics, just as crude norms have dominated the planning process.

\section{Changes under perestroika}

As well as increases in funding and greater flexibility, it seems likely that the private sector will increase. Private practice has always been allowed, but income from it has been subject to taxation at rates well above the normal state maximum of $13 \%$. There is a move

\section{Health care in the USSR}

Health care is provided in hospitals and in polyclinics, the last a combination of general practice and the outpatients department. Some polyclinics are in hospitals, but many, in rural areas especially, are separate. A district has a catchment population of roughly 350000 , with polyclincs covering a tenth of this. The hospital's chief manager is known as the chief doctor so clinician managers are an established feature.

Hospitals get their money from the state, from companies and enterprises, and from various "voluntary" sources. In $19874 \%$ of national income was spent on health care, and the government hopes to double this by 2000 . Before perestroika planning was based on bed norms per hospital and per head of population and on the number of medical specialists per head. Now more sensitive indicators of the health care needs of a population may be used, based, for example, on patterns of disease.

People's access to health care via the polyclinics is reasonably good, combining primary care and some aspects of hospital care, such as diagnosis.

- Hospitals are short of modern equipment, drugs, and disposable items

- Wards are generally overcrowded

- Many hospitals are in buildings that were built for other purposes

- Ordinary beds rather than hospital beds are provided in many hospitals

- Only a third of rural hospitals have a hot water supply.

The overall theme of perestroika as applied to the health care system is accompanied by the final jettisoning of the Stalinist belief that welfare outputs were a drain on the productive economy. Now investment in health is seen as necessary for a strong economy. The founding creed of the USSR naturally includes the notions of the welfare state and of medical care as a right. In consequence, the new philosophy is a return to one of the USSR's founding beliefs.

The aim of the pilot project on hospital financing that I mentioned at the beginning is to provide an incentive for the efficient delivery of care and in particular to reduce length of stay, which against international trends has been rising recently in the USSR. If the hospital earns a surplus it is allowed to keep the money-which may be carried over to the next year-and is particularly encouraged to spend a surplus on new and better equipment. Greater flexibility in staffing is also to be allowed, which should encourage better use of staff time. A particular problem in the USSR is that doctors often have to perform tasks which would be done by other medical staff in the West. Although there were more doctors per 10000 population than any other country by the late 1970 s, there is a much smaller proportion of support staff.

The other side of the coin is, of course, "running out of money." If a polyclinic's budget is cash limited it will give the general practitioner an incentive to practise preventive medicine and to prevent the extensive use of emergency services. It is unclear how and when institutions which run out of money will be 
bailed out. A degree of central control will be maintained as the finance department of the ministry will estimate the relevant price, implying that price will not be the criterion of competition by hospitals to gain referrals (and money) from polyclinics. Hospitals which dispute the department of health prices - for example, claiming that they need more reimbursement for a particular procedure-can take up the matter with the department.

\section{The USSR is ahead of Britain}

In order to reduce patients' length of stay and referrals and emphasise prevention general practitioner budgets have been advocated in the United Kingdom. The irony is that the USSR is ahead of us in instituting a pilot project. The problems as well as the opportunities-including the cash limiting of primary care-are also being confronted in the Soviet Union. But how much actual competition will result? Is it reasonable to expect, for example, that polyclinics will change their patterns of referral to hospital? Officially, it is pointed out that this can be done only in coordination with the patient. But a polyclinic is based

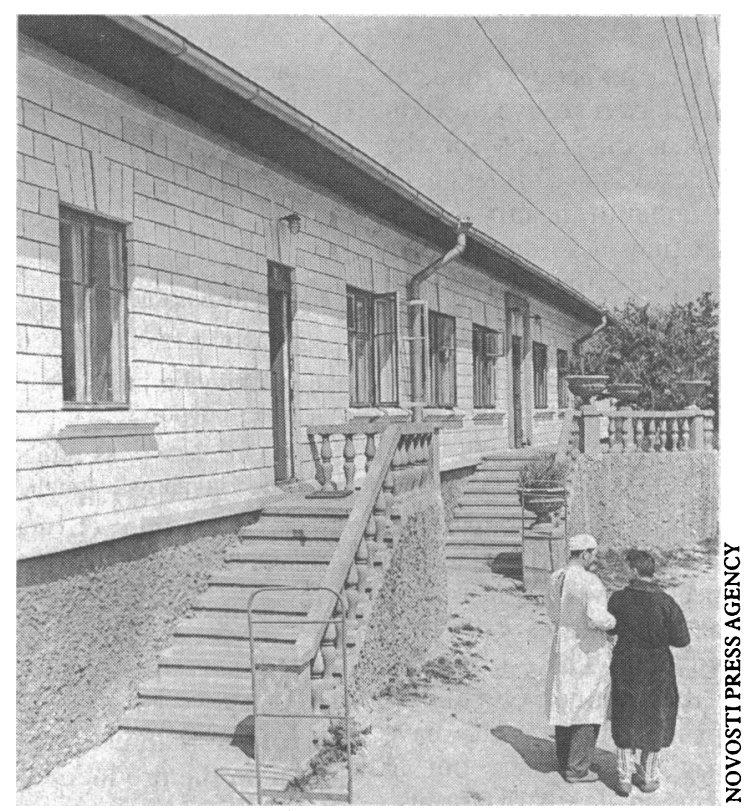

Michurin collective farm hospital in Moldavia

\section{Providing health care}

Providing medical services and health care personnel in rural areas is as much a problem in the USSR as in Western countries. Newly qualified doctors are assigned for three years to rural areas. Despite the fact that they are provided with extra money and other perks, the turnover is high. Chazov has admitted that many doctors are poorly trained. The medical curriculum is going to be lengthened, and those who fail will be awarded an assistant's (feldscher's) diploma only. Assessment in mid career will also be introduced.

- A doctor who has been qualified for five years will typically receive $220-230$ roubles a month ( $\$ 220$ at the official rate, though the rate on the black market is now about $£ 1=10$ roubles), much less than the average industrial worker

- Nurses are paid about 90 roubles a month

- The average daily cost of hospital care in Leningrad is around 90 roubles.

in a hospital and it might be naive to expect it to strike out on its own and refer elsewhere.

While basic pay will continue to be set centrally, as will basic manpower plans, greater pay flexibility may be seen in a devolution of certain decisions about extra increments to the pay of hospitals' chief doctors. As in the United Kingdom, trade unions and other interested organisations are consulted about changes in manpower and conditions. The general rule is that individuals cannot be sacked but must, after considerable negotiation, be transferred to another job in the health care system.

Under Gorbachev perestroika is motivated by a desire to reduce mechanistic bureaucracy and to stimulate greater initiative and enterprise, to be achieved partly by the decentralisation of decision making and budget holding in industry, including the health care system. There will be gainers and losers. In the short term static wages and rising prices as elements of the market are introduced, coupled with some people gaining financially, may cause dissatisfaction at the same time as liberating people's talents. This is likely to occur in health care as well as in the economy as a whole. The prospects for perestroika in health care are therefore bound up with wider social, economic, and political issues, and the developing constellation of contrasting forces will be fascinating to observe.

(Accepted 8 February 1989)

\section{ANY QUESTIONS}

What should be the management of a symptomless woman whose routine cervical smear shows the presence of actinomyces-like organisms; she is using an intrauterine contraceptive device?

This subject was well reviewed by McEwan in $1986 .{ }^{1}$ He points out that cervical cytology is an inaccurate-method for diagnosing the presence of this organism, leading to both false negative and false positive results. Nevertheless, "it is doubtful whether common sense allows this to be ignored whatever the scientific background"-in view of the fact that frank actinomycosis is characterised by an insidious onset and leads to severe illness with multiple pelvic abscesses. The latter condition is, however, rare, with only 200 cases of this disease reported before 1967 and only 30 between 1967 and 1980-although all of the latter were related to the intrauterine device.

McEwan quotes our study at the Margaret Pyke Centre, which showed that removal of the device, whether or not a new copper device was inserted, led to the disappearance of actinomyces-like organisms during monitoring by subsequent cervical smears at six to 12 months. ${ }^{2}$ Our subsequent experience has confirmed the disappearance of the organisms in almost every case, though not invariably, as first reported.
The follow up of all women with intrauterine devices is essential, and this point should be made clear before insertion. Symptoms often considered minor, such as episodes of pelvic pain, dyspareunia, irregular bleeding, and undiagnosed discharge, need to be considered seriously as possible indicators of pelvic infection of an insidious kind. If actinomyces is also shown on cervical cytology the threshold for removing the device (and culture) should be low. If there are positive results in a symptomatic patient specialist advice should be taken and prolonged courses of amoxycillin or tetracycline in high dosage are required.

When there are no symptoms it would be appropriate merely to exchange the device for a new copper one. The woman needs careful follow up with a smear at six months and specific instructions to return earlier should relevant symptoms occur. If repeat smears at six and 12 months are negative it is our policy to return to the routine cytology frequency for healthy women. - JOHN GUILLEBAUD, gynaecologist, London

1 McEwan J. ALOs, actinomyces, actinomycosis and intrauterine devices: some recent findings reviewed. British foumal of Family Planning 1986;12:48-50.

$2 \mathrm{MaOK}$, Guillebaud J. Influence of removal of intrauterine devices on colonization of the cervix by actinomyces-like organisms. Contraception 1984;30:535-44. 